\title{
Thermochemical Performance of a Lightweight Charring Carbon Fiber Reinforced Plastic
}

\author{
By Keiichi OKuYAma, ${ }^{1)}$ Sumio Kato ${ }^{2)}$ and Hiroaki OHYA ${ }^{3)}$ \\ ${ }^{1)}$ Kyushu Institute of Technology, Kitakyushu, Japan \\ ${ }^{2)}$ University of the Ryukyus, Nishihara, Japan \\ ${ }^{3)}$ Kawasaki Heavy Industries, Ltd., Kakamigahara, Japan
}

(Received March 16th, 2012)

\begin{abstract}
A new class of lightweight carbon fiber reinforced plastic (CFRP) — the lightweight ablator series for transfer vehicle systems (LATS) - has recently been developed. The LATS is fabricated by heating and pressurizing a material in which resin is impregnated in the laminated carbon fiber felt. A characteristic required to ensure the excellence of a conventional lightweight CFRP ablator of the LATS is the simplicity of the resin impregnation process. Since dried bulk density can be easily controlled, this manufacturing method is beneficial for use in the aerospace industry. Here, the ablation characteristics of this material under high-enthalpy airflow are described by a recently developed computer code to simulate the one-dimensional transient thermal behavior. The validity of the mathematical model and the applicability of the ablation code are then discussed by comparing the simulated and experimental results of arc-heated tests with the LATS. A new index adopted in this study predicted the mass loss rate; the measured and estimated values of the total mass loss rate in various test conditions are in good agreement. Thus, a heated LATS material shows excellent performance characteristics for use in re-entry vehicles, and its surface and in-depth temperatures can be estimated using the developed analysis code.
\end{abstract}

Key Words: Heat Shield System, Ablator, Carbon Fiber Reinforced Plastic (CFRP), Re-entry

\section{Nomenclature}

$A_{k}$ : collision frequency, $1 / \mathrm{s}$

$B_{k}$ : activation temperature, $\mathrm{K}$

$C_{0}$ : diffusion-controlled mass-transfer constant, $\mathrm{kg}^{0.5} / \mathrm{m}^{2}$

$c_{p}$ : isobaric specific heat, $\mathrm{J} /(\mathrm{kg} \mathrm{K})$

$C_{\infty}$ : isobaric specific heat, $2.3 \times 10^{3} \mathrm{~J} /(\mathrm{kg} \mathrm{K})$

$D$ : temperature, $800 \mathrm{~K}$

$D_{1}$ : outer diameter of specimen, $\mathrm{m}$

$D_{2}$ : inner diameter of specimen, $\mathrm{m}$

$f_{k}$ : weighting factor

$h$ : enthalpy, $\mathrm{J} / \mathrm{kg}$

$k$ : thermal conductivity, $\mathrm{W} /(\mathrm{m} \mathrm{K})$

$L$ : recession length, $\mathrm{m}$

$\dot{m}$ : mass loss rate, $\mathrm{kg} /\left(\mathrm{m}^{2} \mathrm{~s}\right)$

$p$ : pressure, $\mathrm{Pa}$

$\dot{q}$ : heat flux, $\mathrm{W} / \mathrm{m}^{2}$

$R_{B}$ : correction radius of specimen surface, $\mathrm{m}$

$S$ : surface recession, $\mathrm{m}$

$\dot{S}:$ surface recession rate, $\mathrm{m} / \mathrm{s}$

$T$ : temperature, $\mathrm{K}$

$t$ : time, $\mathrm{s}$

$V:$ velocity, $\mathrm{m} / \mathrm{s}$

$x$ : moving coordinate or in-depth distance from receding surface, $y-S, \mathrm{~m}$

$y$ : stationary coordinate or in-depth distance from initial front surface, $\mathrm{m}$

$\Delta h_{\text {pyro }}$ : heat of pyrolysis per gas produced, $\mathrm{J} / \mathrm{kg}$

$\varepsilon$ : surface emissivity $\phi_{\text {blow }}$ : blowing correction factor

$\mu_{k}$ : reaction order

$\rho$ : density, $\mathrm{kg} / \mathrm{m}^{3}$

$\sigma$ : Stefan-Boltzmann constant, $5.67 \times 10^{-8} \mathrm{~W} /\left(\mathrm{m}^{2} \mathrm{~K}\right)$

$\theta$ : diffusion-controlled mass-transfer modulus, $\mathrm{kg}^{0.5} / \mathrm{m}^{2}$

Subscript

$a b$ : ablation

ch: of char

$c w$ : cold wall

$g$ : pyrolysis gas

$m$ : virgin material

$n$ : net

$p$ : pyrolysis

PICA: phenolic impregnated carbon ablator

$r$ : recovery

ref: reference $\left(T_{\text {ref }}=300 \mathrm{~K}\right)$

$s$ : surface

$s t$ : at stagnation point

$t$ : total

$u$ : at wall underside

$v$ : of virgin material

$w$ : at wall

\section{Introduction}

Carbon fiber reinforced plastic (CFRP), which is a composite material made of carbon fiber and resin, is widely used as a heat shield material in the aerospace industry. The Galileo probe deceleration module of NASA's Jupiter explorer was designed for a maximum heat flux of approx- 
imately $300 \mathrm{MW} / \mathrm{m}^{2}$ and exposed to an actual maximum heat flux of $134 \mathrm{MW} / \mathrm{m}^{2} .^{1,2)}$ The external surface of this spacecraft was covered with a high-density CFRP, whose virgin material density was $1,448 \mathrm{~kg} / \mathrm{m}^{3}$. ${ }^{2)}$ This high-density CFRP was used for the return-entry module (REM) capsule of Japan's unmanned space experiment recovery system (USERS). ${ }^{3,4)}$ Figure 1 shows a diagram of the USERS, which consists of the service module (SEM) and REM capsule. ${ }^{3)}$ The REM capsule was carried to Earth orbit by the H2A rocket on September 10, 2002, and successful re-entry into the atmosphere took place on May 30, 2003. ${ }^{3}$

NASA previously developed a lightweight CFRP called the phenolic impregnated carbon ablator (PICA), which has a density that ranges from 224 to $1,041 \mathrm{~kg} / \mathrm{m}^{3}{ }^{5,6)} \mathrm{A}$ PICA with a density of $270 \mathrm{~kg} / \mathrm{m}^{3}$ was used as the heat shield material for the Stardust spacecraft, ${ }^{7,8)}$ which collected a sample from the comet Wild-2. Although this spacecraft was exposed to approximately $8.5 \mathrm{MW} / \mathrm{m}^{2}$ of severe heat flux, it was able to return safely. ${ }^{7,8)}$ The lightweight PICA functioned perfectly as the heat shield material.

Recently, Okuyama et al. developed a new lightweight CFRP called the lightweight ablator series for transfer vehicle systems (LATS), ${ }^{9-14)}$ which is made of a carbon fiber felt and resin with a manufacturing method different from that of PICA. The density of the LATS ranges between approximately 200 and $1,500 \mathrm{~kg} / \mathrm{m}^{3}$; such LATS materials are exposed to heat fluxes of approximately $200 \mathrm{~kW} / \mathrm{m}^{2}$ to $11 \mathrm{MW} / \mathrm{m}^{2}$. Data on the thermal behaviors and performance of LATS were obtained by carrying out such heating tests. From the results of these tests, the LATS were considered to function as a heat shield material in a severe environment of high-enthalpy flow. In this paper, the thermal response and ablation characteristics of the LATS in such an environment are described.

Kato et al. previously developed a computer code to analyze charring ablation and thermal responses. ${ }^{15,16)}$ This code simulates the one-dimensional transient thermal behavior of charring materials. In this study, this analysis code is improved to deal with lightweight heat shield materials. A mathematical model for this charring ablation code including its basic equations is outlined, and the computational method of ablation analysis is revealed. Subsequently, the validity of the mathematical model and the applicability

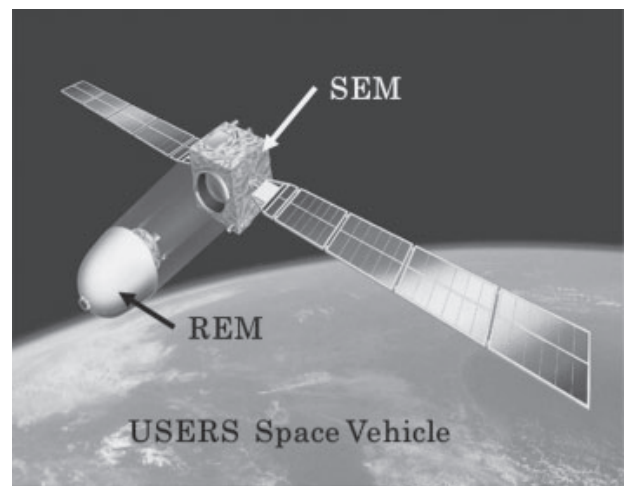

Fig. 1. Diagram of the USERS space system. of the one-dimensional ablation code are discussed based on an evaluation of a comparison between the simulated and experimental results of the arc-heated test. A new index adopted in this study is shown to predict the mass loss rate. A key purpose of the study is to confirm that the new index can be exploited to evaluate heat shield performance.

\section{Materials}

The LATS is fabricated by heating and pressurizing a material in which resin is impregnated in the carbon fiber felt. The virgin carbon felt is a polyacrylonitrile (PAN), pitch or rayon fiber whose dried bulk density is approximately 20$1,000 \mathrm{~kg} / \mathrm{m}^{3}$. The resin is mainly a phenol or silicone resin. The LATS used for the present study is composed of a PAN carbon fiber felt with a bulk density of approximately $100 \mathrm{~kg} / \mathrm{m}^{3}$ and a phenol resin. Heating and pressurizing are mainly carried out using the hot plate press method or the autoclave manufacturing method. The bulk density of the LATS can be adjusted by varying the quantity of resin impregnated into the felt and the pressure force of the hot plate press. In the present study, the bulk densities of the LATS are approximately $200-800 \mathrm{~kg} / \mathrm{m}^{3}$.

There are many kinds of lightweight ablators which are made of fiber reinforced plastics with a porous structure; typical materials are the Acusil series for the Comets program, the AVCORT5026 for the Apollo program, the SLRCA series for the Mars Pathfinder program, the SPA for the MIRKA program, the AQ60 for the Huygens program, the PICA for the Stardust program and so on. The only lightweight ablator which uses a carbon fiber among these is the PICA. This PICA is formed by a technique of making one sheet of thick carbon form with the impregnation a phenolic resin. The LATS is the accumulation of thin carbon felts that are impregnated with a resin. The production techniques of the PICA and the LATS are different.

Figures 2 and 3 show the temperature dependences of thermal conductivity and isobaric specific heat, respectively. The thermal conductivities from room temperature to $573 \mathrm{~K}$ and beyond $573 \mathrm{~K}$ are determined by the guarded hot plate (GHP) method and the laser flash method, respec-

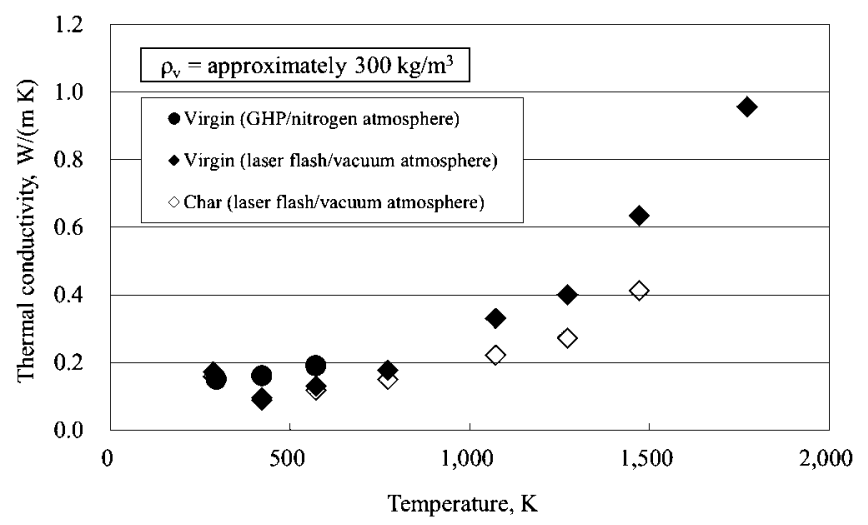

Fig. 2. Relationship between measured thermal conductivity and temperature. 


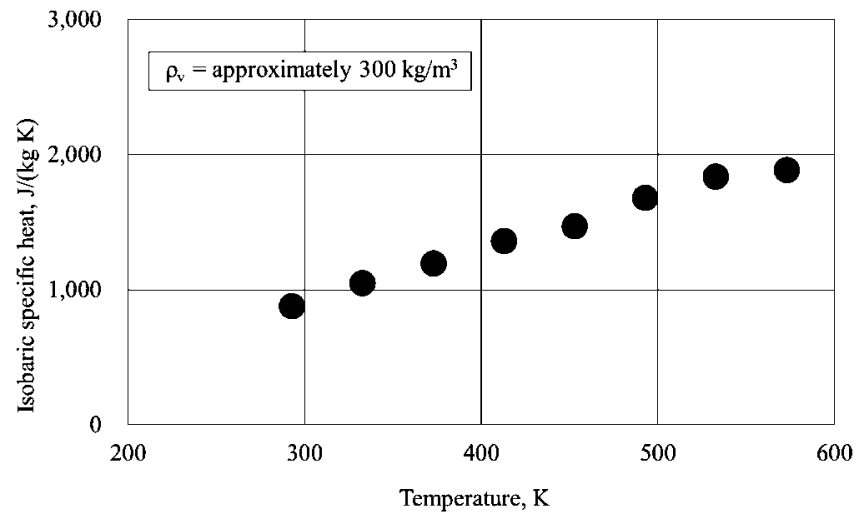

Fig. 3. Relationship between measured isobaric specific heat and temperature.

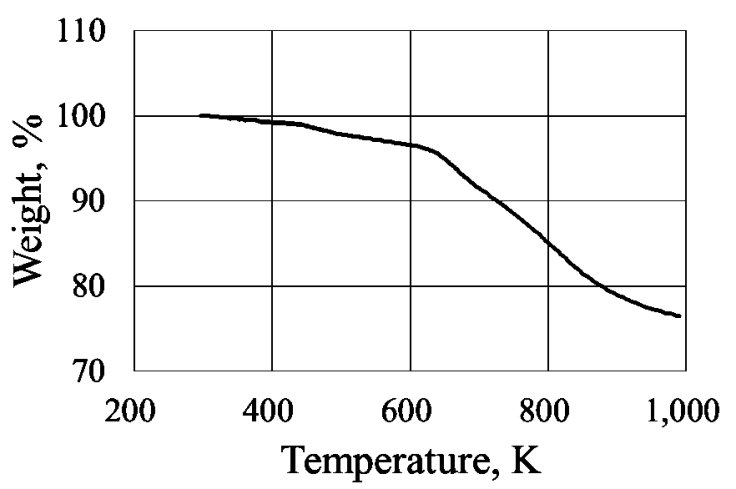

Fig. 4. Measured thermogravimetry (TG) data of LATS in an argon gas environment.

tively. Values for the isobaric specific heat from room temperature to $573 \mathrm{~K}$ were determined with an adiabatic scanning calorimeter, ULVAC SH3000. A fully carbonized LATS fabricated at $1,773 \mathrm{~K}$ in a vacuum environment is also used in these measurements.

Figure 4 shows thermogravimetry (TG) data for the LATS from room temperature to $1,000 \mathrm{~K}$ in an argon gas environment. These data are acquired using a DSC Q2000 (TA Instruments Inc.).

\section{Charring Ablation Analysis}

In section 6.2, the thermal response of the LATS materials is simulated using a one-dimensional charring ablation analysis code. The mathematical model for the code is precisely described in Ref. 14). Here, the basic equations and boundary condition for the mathematical model of the ablation analysis code, which is used in this study, are briefly shown below.

The model is similar to that in Refs. 15) and 16).

\subsection{Basic equations}

The basic equations for charring ablation are well known. ${ }^{14-19)}$ Among those used in the present analysis code, the in-depth energy equation of the ablator is expressed by

$$
\begin{aligned}
\rho c_{p}\left(\frac{\partial T}{\partial t}\right)_{x}= & \frac{\partial}{\partial x}\left(k \frac{\partial T}{\partial x}\right)_{t}+\Delta h_{\mathrm{pyro}}\left(\frac{\partial \rho}{\partial t}\right)_{y} \\
& +\dot{S} \rho c_{p}\left(\frac{\partial T}{\partial x}\right)_{t}+\dot{m}_{g} c_{p}\left(\frac{\partial T}{\partial x}\right)_{t} .
\end{aligned}
$$

In Eq. (1), the $x$ coordinate system moves because of the surface recession with the origin fixed to the surface, whereas the $y$ coordinate system is stationary with the origin fixed to the ablator surface before heating. The terms in Eq. (1) represent, from left to right, the sensible energy accumulation rate, net conduction rate, pyrolysis energy consumption rate, convection rate of sensible energy as a consequence of coordinate motion and net rate of energy convected by the pyrolysis gas passing a point, respectively. The specific heat $k$ and thermal conductivity $c_{p}$ are calculated by

$$
\begin{aligned}
k & =\omega \rho_{v} k_{v}+(1-\omega) \rho_{c h} k_{c h} \\
\omega & =\left(\rho-\rho_{c h}\right) /\left(\rho_{v}-\rho_{c h}\right) \\
\rho c_{p} & =\omega \rho_{v} c_{p v}+(1-\omega) \rho_{c h} c_{p c h} .
\end{aligned}
$$

The equations of mass conservation when the ablator yields the pyrolysis gas and the Arrhenius-type expression for the ablator decomposition rate are described by the following equations, respectively

$$
\begin{aligned}
& \left(\partial \dot{m}_{g} / \partial y\right)_{t}=(\partial \rho / \partial t)_{y} \\
& \left(\frac{\partial \rho}{\partial t}\right)_{y}=-\sum_{k=1}^{N} A_{k} f_{k}\left(\rho_{v}-\rho_{c h}\right)\left(\frac{\rho-\rho_{c h}}{\rho_{v}-\rho_{c h}}\right)^{\mu_{k}} \exp \left(-\frac{B_{k}}{T}\right)
\end{aligned}
$$

where $\mu_{k}$ is the reaction order, $A_{k}$ is the weighting factor, $f_{k}$ is the collision frequency and $B_{k}$ is the activation temperature. These values are assumed to be constant.

\subsection{Boundary condition}

The conditions at the ablating surface are determined by the energy balance. The energy balance equation is shown below. ${ }^{19)}$

$$
\begin{aligned}
\dot{q}_{\text {net }}= & \dot{q}_{c w}\left(1-h_{w} / h_{r}\right) \phi_{\text {blow }}-\varepsilon \sigma\left(T_{w}{ }^{4}-T_{\text {ref }}{ }^{4}\right) \\
& -\dot{m}_{a b}\left(h_{w}-h_{u}\right)
\end{aligned}
$$

The terms in Eq. (6), from left to right, represent the rate of energy conduction into the ablator at the surface, convective heat transfer rate in which a correction for blowing is included, net heat flux re-radiated from the surface and enthalpy change rate of surface ablation products leaving the surface, respectively.

\section{Prediction of Mass Loss Rate}

Metzger et al. clarified the mass loss characteristics of graphite in heated air. ${ }^{20)}$ According to their study, the mass loss of graphite occurs in three regions. The first is the ratecontrolled oxidation region in the temperature range below approximately $1,500 \mathrm{~K}$, where the surface material mainly dissipates as a result of its oxidation by air. The second is the diffusion-controlled oxidation region in the temperature range above approximately $1,500 \mathrm{~K}$. Park demonstrated that the surface mass loss of the graphite in both of these regions 
chiefly advances according to the reaction $\mathrm{C}+\mathrm{O} \rightarrow \mathrm{CO} .{ }^{21)}$ The third is the sublimation region in the temperature range above approximately $3,000 \mathrm{~K},{ }^{20}$ ) where the surface mass loss of graphite predominantly occurs through the sublimation of carbon: 3C (Solid) $\rightarrow$ C3 (Gas).

Meanwhile, based on the mass loss characteristics of the graphite, Potts studied the mass loss characteristics of carbonized CFRP in air. ${ }^{19,22)}$ Okuyama et al. confirmed that the rate-controlled oxidation and diffusion-controlled oxidation regions exist when CFRP is exposed to air or nitrogen under approximately $3,000 \mathrm{~K} .^{23)}$ In the diffusion-controlled oxidation region, Metzger et al. expressed the total mass loss rate $\dot{m}_{t}$ in the diffusion-controlled oxidation region of the graphite as follows ${ }^{20)}$

$$
\dot{m}_{t}=C_{0} \sqrt{P_{s t} / R_{B}}
$$

where $C_{0}$ is the diffusion-controlled mass-transfer constant $\left(\mathrm{kg}^{0.5} / \mathrm{m}^{2}\right), P_{s t}$ is the stagnation pressure $(\mathrm{Pa})$ and $R_{B}$ is the curvature radius of the specimen. When the front surface of the specimen is flat, the correction radius $R_{B}$ is 2.46 times the actual radius. ${ }^{20)}$

Given that the graphite does not contain resin, the diffusion-controlled mass-transfer constant $C_{0}$ is fixed. However, the LATS contains resin, and its quantity depends on the density. The resin of a heated LATS decomposes; a portion of the resin becomes gas and covers the material surface.

Metzger's theory cannot be applied to CFRP, which contains a resin that undergoes thermal decomposition by heating. Therefore, prediction of the total mass loss rate $\dot{m}_{t}$ of CFRP is difficult. Okuyama et al. confirmed the mass loss of CFRP in a nitrogen gas atmosphere. ${ }^{23)}$ The experimental conditions $\mathrm{X}$ through $\mathrm{Z}$ are used in this study. A virgin CFRP used for test condition $\mathrm{X}$ has a density of approximately $1,470 \mathrm{~kg} / \mathrm{m}^{3}$ and contains $20 \mathrm{wt} \%$ phenolic resin. In conditions $\mathrm{Y}$ and $\mathrm{Z}$, the heating test is performed with test pieces that underwent the heating test in condition $\mathrm{X}$. Condition $\mathrm{Y}$ is insufficient for achieving complete thermal decomposition of the phenolic resin left in the test pieces that underwent the heating test in condition X. Finally, condition $\mathrm{Z}$ almost completely carbonizes CFRP pieces and lowered their density to approximately $1,180 \mathrm{~kg} / \mathrm{m}^{3}$.

In a nitrogen atmosphere, the relation between the total mass losses $\dot{m}_{t}$ of the carbonized CFRP heated to a temperature below $3,000 \mathrm{~K}$ and the surface temperature can be divided into two distinct regions-the rate-controlled and diffusion-controlled regions. ${ }^{23)}$

The total mass loss rates $\dot{m}_{t}$ of the carbonized CFRP in a nitrogen atmosphere are shown in the following equations; for conditions $\mathrm{X}, \mathrm{Y}$, and $\mathrm{Z}, \dot{m}_{t}=2.44 \times 10^{-5}\left(P_{e} / R_{B}\right)^{0.5}$, $1.72 \times 10^{-5}\left(P_{e} / R_{B}\right)^{0.5}$ and $0.713 \times 10^{-5}\left(P_{e} / R_{B}\right)^{0.5}$, respectively. ${ }^{23)}$ These results of Okuyama's study clarify that the total mass loss rate $\dot{m}_{t}$ becomes small as the amount of resin inside CFRP decreases. Therefore, Eq. (7) is modified to Eq. (8).

$$
\dot{m}_{t}=\theta \sqrt{P_{s t} / R_{B}}
$$

Here, $\theta$ is named as the diffusion-controlled mass-transfer modulus $\left(\mathrm{kg}^{0.5} / \mathrm{m}^{2}\right)$, which can only be used in the diffusion-controlled regime. This number is a new evaluation index of the heat shield performance of ablators.

\section{Heating Test}

\subsection{Test facility}

Several heating tests are performed using the arc-heating equipment owned by the Japan Ultra High Temperature Material Center (JUTEM), ${ }^{24)}$ the Aerospace Research and Development Directorate (ARD) of the Japan Aerospace Exploration Agency (JAXA), ${ }^{25,26)}$ and Deutsches Zentrum für Luft- und Raumfahrt (DLR) of Germany. ${ }^{27)}$

The arc heater of the JUTEM is a Huels-type heater with a maximum discharge power of $20 \mathrm{~kW}$. The arc heaters of the ARD of JAXA and the L3K of DLR are segmented arc heaters with maximum discharge powers of $750 \mathrm{~kW}$ and $6 \mathrm{MW}$, respectively. As for the test gas of this study, air is usually heated using electrical arc discharge to generate a high-temperature plasma stream. These arc heaters allow the determination of test parameters with high reproducibility.

The cold-wall heat flux rate and the pressure of the highenthalpy airflow are measured using a flat face cylindrical copper calorimeter and a Pitot tube that stems the airflow and measures the stagnation pressure. The surface temperature is measured using an infrared thermometer (pyrometer), which is a sensor that detects the infrared radiation from the surface of the material. A photograph of a CFRP surface at the L3K of DLR is shown in Fig. 5.

\subsection{Test conditions and specimens}

Given that the mass loss and the in-depth temperature of the LATS presumably depend on the surface temperature and stagnation pressure, test pieces are subjected to measurements at various surface temperatures and stagnation pressures. The experimental conditions in Table 1 are used to test the LATS. A to $\mathrm{C}$ shows the test conditions of the JUTEM, ARD of JAXA and L3K of DLR, respectively. Under these conditions, the heating tests are performed on test pieces with virgin LATS densities of approximately $200-1,500 \mathrm{~kg} / \mathrm{m}^{3}$ for the JUTEM, $200-700 \mathrm{~kg} / \mathrm{m}^{3}$ for the

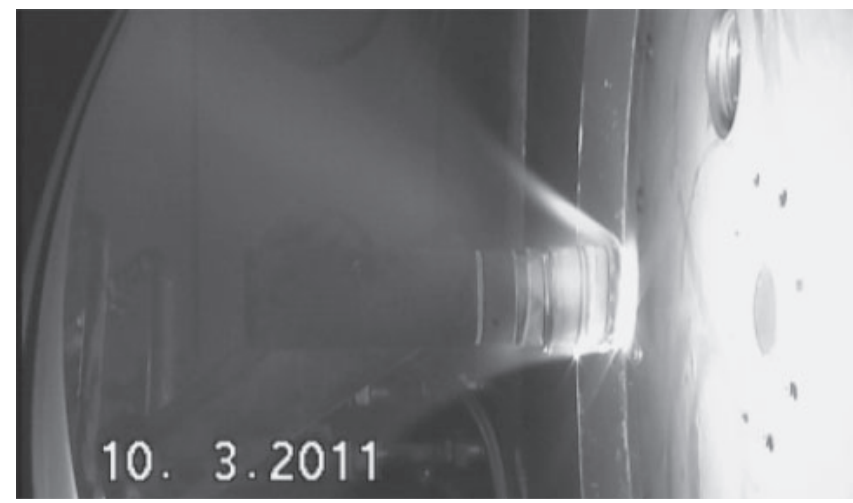

Fig. 5. LATS set in high enthalpy airflow in the L3K of DLR. 
Table 1. Test conditions for measuring thermochemical characteristics of LATS.

\begin{tabular}{|c|c|c|c|c|c|c|c|c|}
\hline \multirow[b]{2}{*}{$\begin{array}{c}\text { Conditions } \\
\text { No. }\end{array}$} & \multicolumn{4}{|c|}{ Specimens } & \multicolumn{4}{|c|}{ Conditions } \\
\hline & No. & $\begin{array}{c}D_{1} \\
\mathrm{~m} \times 10^{-3}\end{array}$ & $\begin{array}{c}t_{1} \\
\mathrm{~m} \times 10^{-3}\end{array}$ & $\begin{array}{l}\text { Density } \\
\mathrm{kg} / \mathrm{m}^{3}\end{array}$ & $\begin{array}{c}\text { Duration } \\
\mathrm{s}\end{array}$ & $\begin{array}{c}\text { Stagnation } \\
\text { pressure } \\
\mathrm{kPa}\end{array}$ & $\begin{array}{c}\text { Enthalpy } \\
\mathrm{MJ} / \mathrm{kg}\end{array}$ & $\begin{array}{c}\text { Heating } \\
\text { rate } \\
\mathrm{MW} / \mathrm{m}^{2}\end{array}$ \\
\hline \multirow[t]{5}{*}{ A } & J3-1 & 29.8 & 19.4 & 344 & 150 & 0.533 & 27.4 & 1.0 \\
\hline & $\mathrm{J} 3-2$ & 29.8 & 19.4 & 331 & 150 & 0.533 & 27.4 & 1.0 \\
\hline & J5-1 & 29.7 & 19.8 & 495 & 150 & 0.533 & 27.4 & 1.0 \\
\hline & J5-2 & 29.7 & 19.7 & 491 & 150 & 0.533 & 27.4 & 1.0 \\
\hline & J5-3 & 29.8 & 19.8 & 499 & 150 & 0.853 & 27.4 & 2.0 \\
\hline \multirow[t]{4}{*}{ B } & A3-1 & 34.0 & 19.6 & 296 & 60 & 1.9 & 12.8 & 0.97 \\
\hline & A3-2 & 34.0 & 19.7 & 287 & 60 & 4.6 & 18.8 & 2.0 \\
\hline & A5-1 & 34.0 & 19.9 & 544 & 60 & 1.9 & 12.8 & 0.98 \\
\hline & A5-2 & 34.1 & 20.1 & 531 & 110 & 4.6 & 18.8 & 1.97 \\
\hline \multirow[t]{5}{*}{$\mathrm{C}$} & D3-1 & 45.9 & 40.0 & 341 & 15 & 19.0 & 14.5 & 5.3 \\
\hline & D3-2 & 45.9 & 40.2 & 296 & 20 & 47.5 & 14.5 & 8.3 \\
\hline & D5-1 & 45.9 & 39.9 & 566 & 10 & 47.5 & 14.5 & 8.3 \\
\hline & D5-2 & 45.9 & 39.9 & 536 & 10 & 85.0 & 14.5 & 11.1 \\
\hline & D5-3 & 45.8 & 39.9 & 561 & 15 & 19.0 & 14.5 & 5.3 \\
\hline
\end{tabular}

The LATS with the virgin density ranging between approximately $200-700 \mathrm{~kg} / \mathrm{m}^{3}$ were heated to evaluate the relationship between the densities of virgin and carbonized materials.

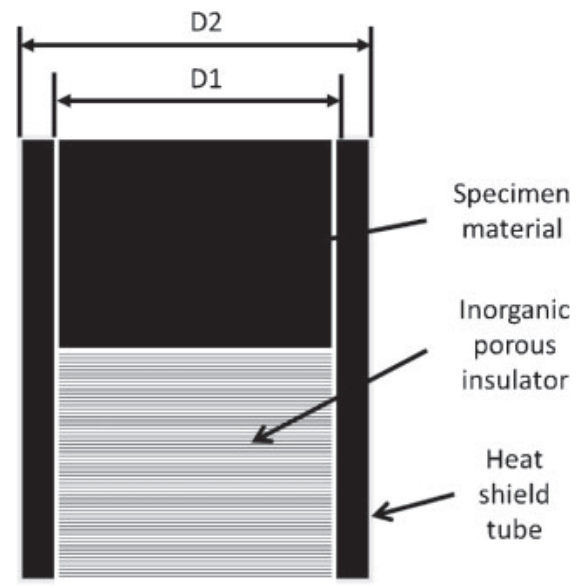

Fig. 6. Schematic outline of the specimen for the heating test.

ARD of JAXA, and $200-600 \mathrm{~kg} / \mathrm{m}^{3}$ for the L3K of DLR. The main purpose of the heating test at the JUTEM is to acquire density data for various fully carbonized LATS specimens. The main purpose of the tests at the JAXA and DLR is to understand the thermochemical performance of the LATS under a high-enthalpy environment. Under this wide range of conditions, the time courses of the surface and in-depth temperatures are acquired, where the heat flux and duration are $500 \mathrm{~kW} / \mathrm{m}^{2}-11.1 \mathrm{MW} / \mathrm{m}^{2}$ and $10-300 \mathrm{~s}$, respectively.

The cylindrical specimen assembly used for the heating test is depicted schematically in Fig. 6, and details of the structure are indicated in Table 2 . The assembly consists of an evaluated part and a support structure. The virgin LATS material is placed at the front of the evaluated part and subjected directly to frontal heating. The support struc- ture insulates the LATS piece from side heating and reinforces one-dimensional heat flow in the evaluated part. The support structure consists of an outer heat shield tube made of high-density CFRP or Bakelite, and an inorganic porous insulator with low thermal diffusivity. This tube is covered with inorganic cloth to reduce heating of the specimen from the side. Using these procedures, a onedimensional analysis becomes possible. In Table 2, $D_{1}$ and $D_{2}$ refer to the diameters of the outer heat shield tube and the LATS material, respectively. Measurements of the weight, diameter, and thickness are taken before and after each test to determine the surface recession and mass loss of each model assembly.

\section{Results and Discussion}

\subsection{Thermochemical performance}

Several LATS materials are heated under the conditions shown in Table 1. As noted previously, the heating tests are carried out at three facilities; i.e., the JUTEM, ARD of JAXA and L3K of DLR. The two common LATS densities used in the heating tests implemented at these three facilities are approximately 300 and $500 \mathrm{~kg} / \mathrm{m}^{3}$.

The relationship between the densities of virgin and carbonized LATS is shown in Fig. 7. In the virgin density of the LATS ranging between approximately 200-700 $\mathrm{kg} / \mathrm{m}^{3}$, the carbonized LATS density $\rho_{c h}$ is expressed as a function of this virgin LATS density $\rho_{m}$ in Eq. (9). All of these data are acquired using the heating test at the JUTEM.

$$
\rho_{c h}=0.716 \rho_{m}
$$

Figure 8 shows that the surface temperatures of the LATS specimens heated under the conditions of Table 1 are ap- 
Table 2. Heating test condition for acquiring thermochemical characteristics of LATS.

\begin{tabular}{|c|c|c|c|c|c|}
\hline \multicolumn{3}{|l|}{ Conditions } & A & B & $\mathrm{C}$ \\
\hline \multicolumn{3}{|l|}{ Facility } & JUTEM & ARD & DLR \\
\hline \multirow{2}{*}{$\begin{array}{l}\text { Support } \\
\text { structure }\end{array}$} & \multicolumn{2}{|c|}{ Diameter $D_{2}, \mathrm{~m} \times 10^{-3}$} & 40 & 40 & 50 \\
\hline & \multicolumn{2}{|c|}{ Outside tube } & \multicolumn{3}{|c|}{ CFRP } \\
\hline \multirow{6}{*}{$\begin{array}{l}\text { Evaluation } \\
\text { part }\end{array}$} & \multicolumn{2}{|c|}{ Diameter $D_{1}, \mathrm{~m} \times 10^{-3}$} & 30 & 34 & 46 \\
\hline & \multirow[t]{4}{*}{ LATS } & Density (virgin), $\mathrm{kg} / \mathrm{m}^{3}$ & \multicolumn{3}{|c|}{ Approximately 300 and 500} \\
\hline & & Density (charred), $\mathrm{kg} / \mathrm{m}^{3}$ & \multicolumn{3}{|c|}{ Approximately 215 and 358} \\
\hline & & $\begin{array}{l}\text { Thermal coductivity at } \\
\text { room temperature } \\
\text { (virgin), } \mathrm{W} / \mathrm{m} / \mathrm{K}\end{array}$ & \multicolumn{3}{|c|}{ Approximately 0.17 and 0.25} \\
\hline & & $\begin{array}{l}\text { Isobaric specific heat at } \\
\text { room temperature } \\
\text { (virgin), } \mathrm{J} /(\mathrm{kg} \mathrm{K})\end{array}$ & \multicolumn{3}{|c|}{ Approximately 880 and 980} \\
\hline & \multicolumn{2}{|c|}{ Porous insulator material } & \multicolumn{2}{|c|}{ Alumina-silica fiber } & CFRP \\
\hline
\end{tabular}

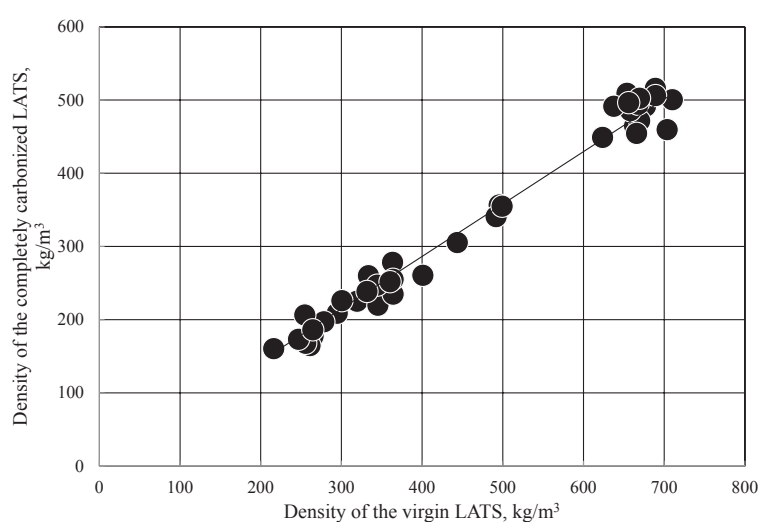

Fig. 7. Relationship between density of virgin LATS and carbonized LATS.

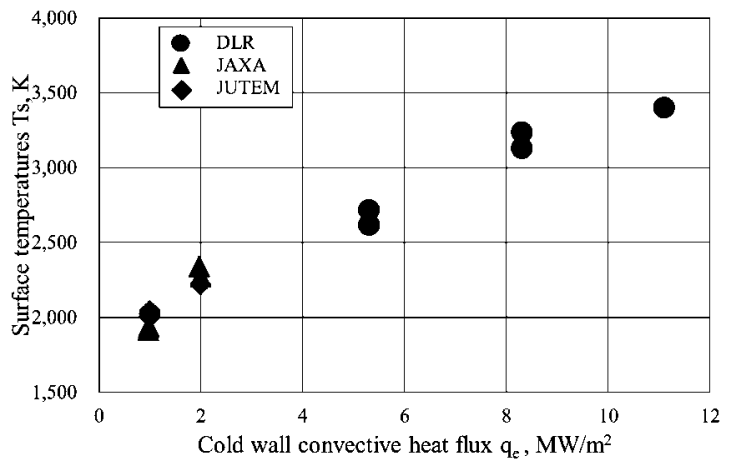

Fig. 8. Relationship between surface temperature of LATS and cold wall convective heat flux.

proximately $1,500-3,500 \mathrm{~K}$. Therefore, these specimens are in the diffusion-controlled oxidation region.

The surface temperatures which are shown in Fig. 8 are measured values in heating ends.

Many researchers have demonstrated the performance of charring ablative materials using the effective heat of ablation $H_{\text {eff }}$ in Eq. (10).

$$
H_{e f f}=\frac{\dot{q}_{c w}}{V_{s} \rho_{m}}
$$

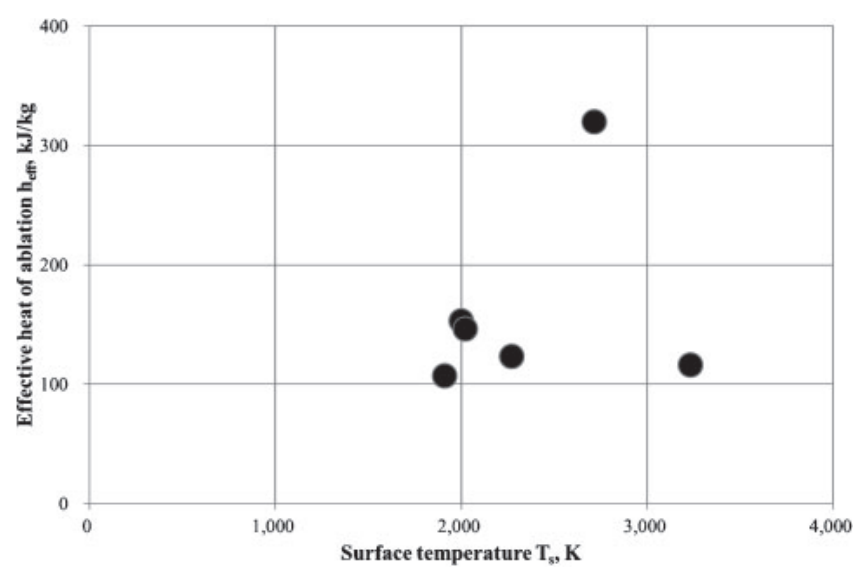

Fig. 9. Relationship between effective heat of ablation $H_{\text {eff }}$ and surface temperature $T_{s}$ of LATS $^{4}$ (density of virgin LATS: approximately $\left.300 \mathrm{~kg} / \mathrm{m}^{3}\right)$.

Here, $\dot{q}_{c w}$ is the stagnation point cold-wall convective heat flux and $V_{s}$ is the surface recession velocity.

Figures 9-11 show the relationships between the surface temperature $T_{s}$ and the effective heat of ablation $H_{\text {eff }}$ of the LATS, the high-density CFRP used as the heat shield material for the REM capsule, ${ }^{4)}$ and the PICA, ${ }^{5,6}$ respectively.

The effective heat of ablation $H_{\text {eff }}$ has been used in many studies to evaluate the thermochemical performance of charring ablators. However, Figs. 9-11 show that $H_{\text {eff }}$ does not strongly depend on the surface temperature $T_{s}$. Hence, it is shown that as the heat flux $\dot{q}_{c w}$ increases, the surface temperature $T_{s}$ increases. Therefore, $H_{e f f}$ is not an index of the charring ablators which is used in severe heating environments.

A model of charring ablative materials is illustrated schematically in Fig. 12. ${ }^{28)}$ The model shows three distinct zones: a surface char layer, a pyrolysis layer and a virgin layer. The total mass loss rate $\dot{m}_{t}$ of the charring ablative material is determined via the following equation. ${ }^{28)}$

$$
\dot{m}_{t}=V_{s} \rho_{c h}+V_{c h}\left(\rho_{m}-\rho_{c h}\right)+V_{p}\left(\rho_{m}-\rho\right)
$$




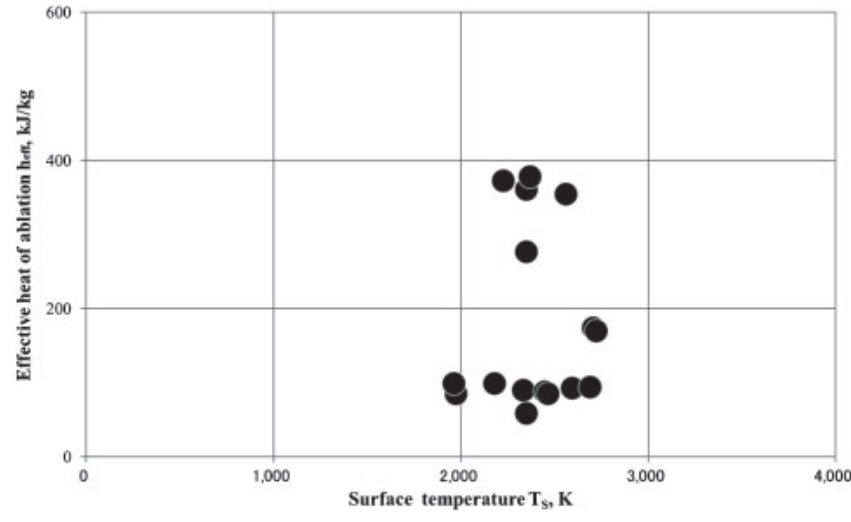

Fig. 10. Relationship between effective heat of ablation $H_{\text {eff }}$ and surface temperature $T_{s}$ of conventional phenolic $\mathrm{CFRP}^{5,6)}$ (density of virgin CFRP: $1,470 \mathrm{~kg} / \mathrm{m}^{3}$ ).

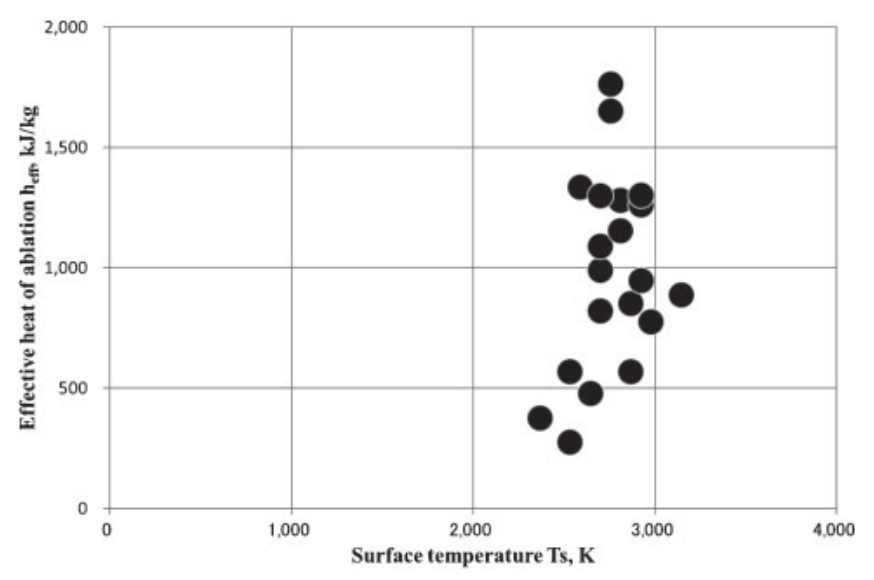

Fig. 11. Relationship between effective heat of ablation $H_{\text {eff }}$ and surface temperature $T_{s}$ of the PICA (density of virgin PICA: approximately $\left.300 \mathrm{~kg} / \mathrm{m}^{3}\right)$.

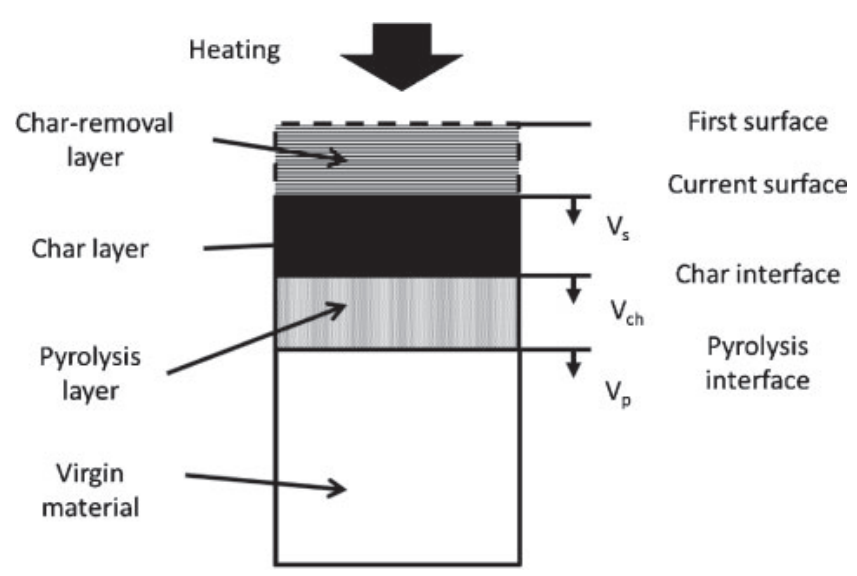

Fig. 12. Ablated model of charring CFRP.

Here, $V_{c h}$ and $V_{p}$ are the char interface and pyrolysis interface velocities, respectively. ${ }^{28)}$ The density $\rho$, which is calculated from Eq. (5), is a value at the pyrolysis interface. In the case of the LATS with the virgin density ranging between approximately $200-700 \mathrm{~kg} / \mathrm{m}^{3}, \rho_{c h}$ is $0.716 \rho_{m}$ and $\rho$ varies from $\rho_{m}$ to $0.716 \rho_{m}$. The first term of this equation constitutes the char-removal rate. The second and third

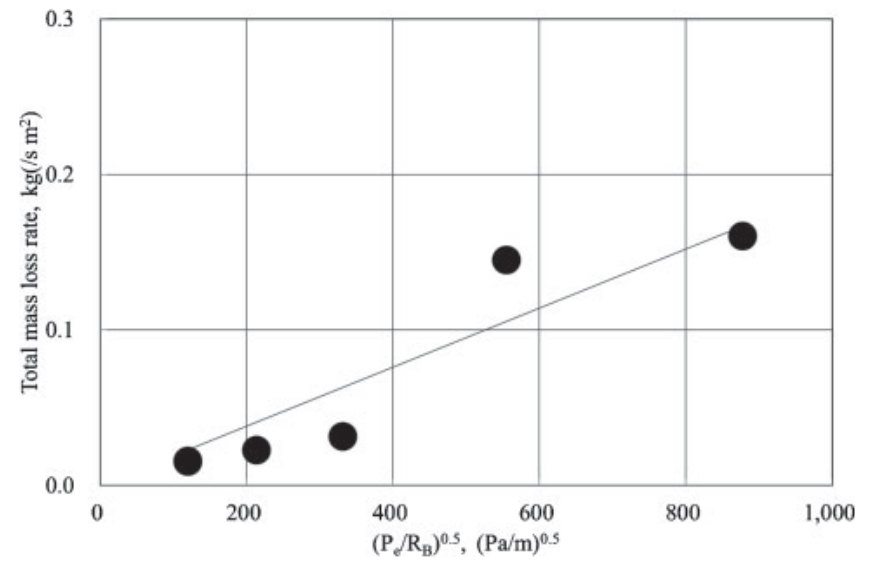

Fig. 13. Relationship between total mass loss rate $m_{t}$ and $\left(P_{e} / R_{B}\right)^{0.5}$ of the LATS (density of virgin LATS: approximately $300 \mathrm{~kg} / \mathrm{m}^{3}$ ).

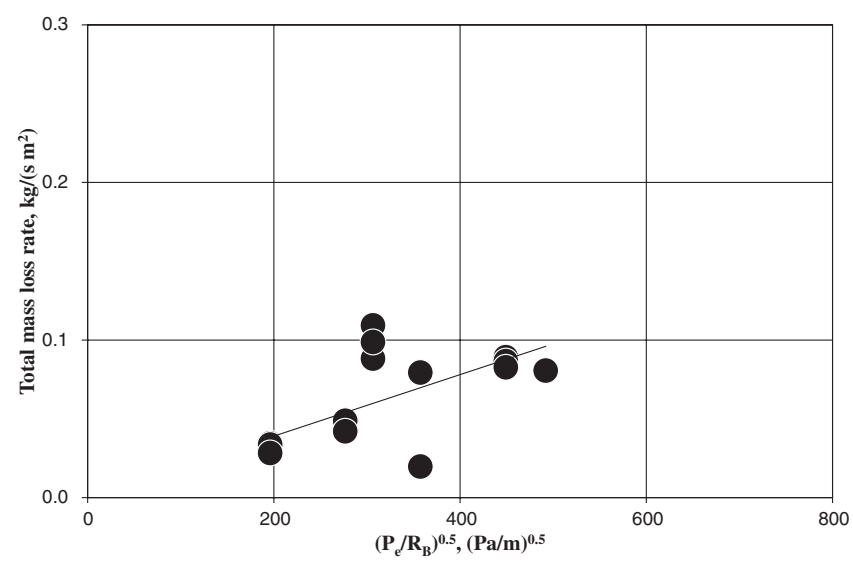

Fig. 14. Relationship between total mass loss rate $m_{t}$ and $\left(P_{e} / R_{B}\right)^{0.5}$ of conventional phenolic CFRP (density of virgin CFRP: $1,470 \mathrm{~kg} / \mathrm{m}^{3}$ ).

terms represent the rates of vapor production in completely and partially degraded materials, respectively.

When the charring ablative material has a very thin pyrolysis zone under all test conditions, the third term of Eq. (11) can be ignored. Note that under steady-state conditions, $V_{s}=V_{c}=V_{p} \equiv V$, and Eq. (11) becomes the following simple equation.

$$
\dot{m}_{t}=V \rho_{m}
$$

Equation (12) is the denominator of Eq. (10). The estimated total mass loss rate $\dot{m}_{t}$, based on measured values of the surface recession speed $V_{c h}$ and virgin density $\rho_{m}$, is not in precise accord with the measured total mass loss rate $\dot{m}_{t}$. It is assumed that the effective heat of ablation $H_{\text {eff }}$ is inaccurate. In the diffusion-controlled oxidation region, it can be said that Eq. (8) is more suitable than Eq. (10) for predicting the total mass loss rate of charring ablative materials.

Figures 13-15 show the relationships between the total mass loss rate $\dot{m}_{t}$ and $\theta$ for the LATS, the high-density CFRP used as the heat shield material for the REM capsule and the PICA, respectively. Moreover, Figs. 13-15 show that $\theta$ values for the LATS, heat shield material and PICA are $20.0 \times 10^{-5}, 19.5 \times 10^{-5}$ and $20.8 \times 10^{-5} \mathrm{~kg}^{0.5} / \mathrm{m}^{2}$, 


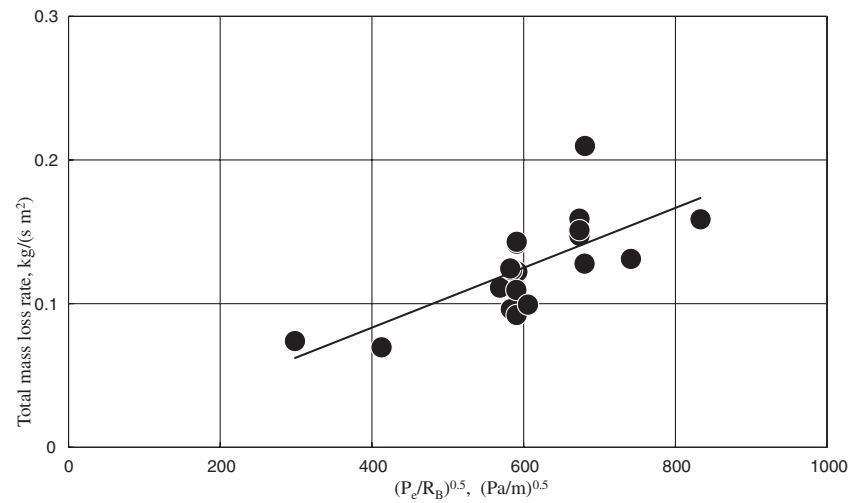

Fig. 15. Relationship between total mass loss rate $m_{t}$ and $\left(P_{e} / R_{B}\right)^{0.5}$ of the PICA (density of virgin PICA: approximately $300 \mathrm{~kg} / \mathrm{m}^{3}$ ).

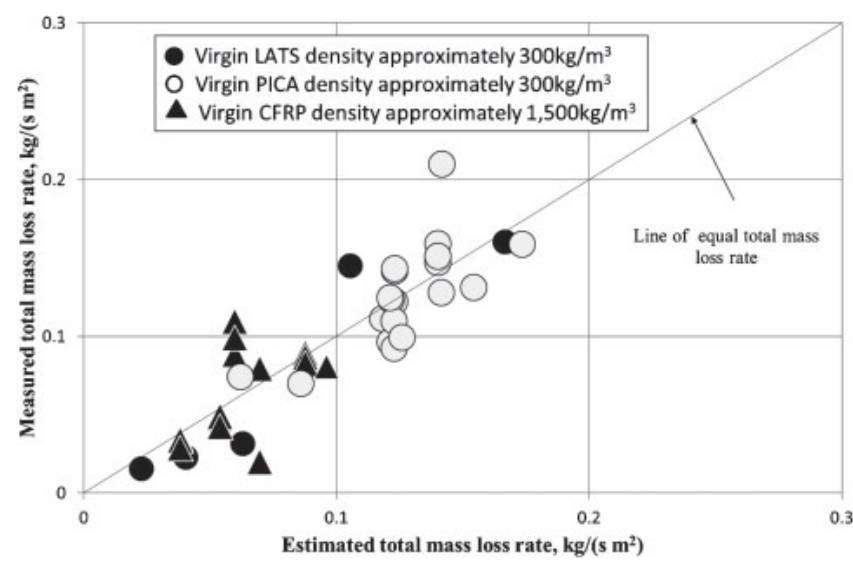

Fig. 16. Relationship between measured and estimated total mass loss rate of charring CFRP.

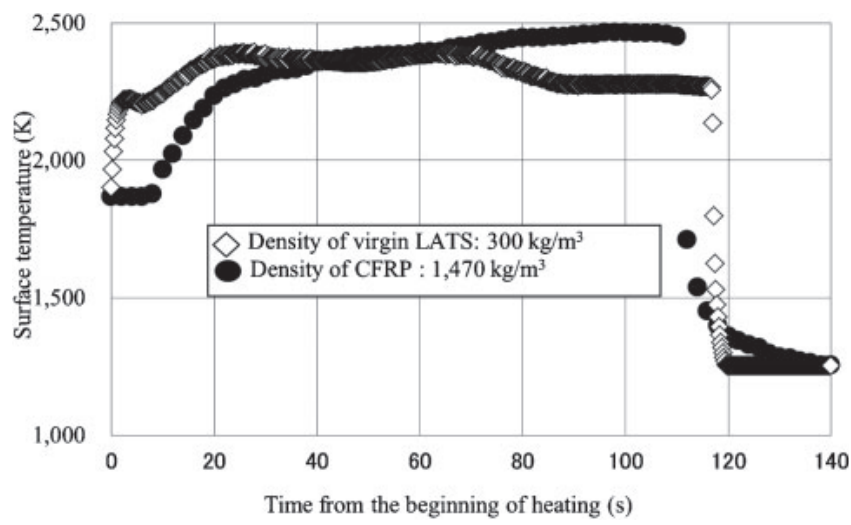

Fig. 17. Time course of surface temperature of the LATS (heating rate: $2.0 \mathrm{MW} / \mathrm{m}^{2}$; duration: $110 \mathrm{~s}$; stagnation pressure: $5.0 \mathrm{~Pa}$; facility: ARD of JAXA) and conventional high-density CFRP (heating rate: $1.9 \mathrm{MW} / \mathrm{m}^{2}$; duration: $110 \mathrm{~s}$; stagnation pressure: $0.5 \mathrm{kPa}$; facility: JUTEM).

respectively. The $\theta$ value of the LATS is approximately identical to that of the heat shield material and the PICA.

The measured and estimated values of the total mass loss rate $\dot{m}_{t}$ in each test condition are shown in Fig. 16 . The values are in good agreement, suggesting that Eq. (8) can be used to estimate the total mass loss rate.

Figure 17 shows the time course of the surface temperature for $120 \mathrm{~s}$ under a heat flux of $2.0 \mathrm{MW} / \mathrm{m}^{2},{ }^{11)}$ whereas

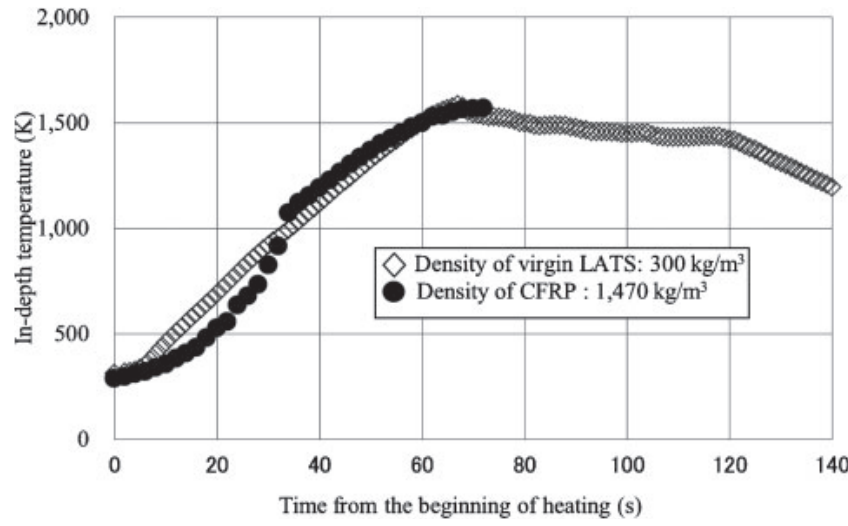

Fig. 18. Time course of in-depth temperature of the LATS (heating rate: 2.0 MW $/ \mathrm{m}^{2}$; duration: $110 \mathrm{~s}$; stagnation pressure: $5.0 \mathrm{~Pa}$; facility: ARD of JAXA) and conventional high-density CFRP (heating rate: $1.9 \mathrm{MW} /$ $\mathrm{m}^{2}$; duration: $110 \mathrm{~s}$; stagnation pressure: $0.5 \mathrm{kPa}$; facility: JUTEM) (thermocouple depth: $5 \mathrm{~mm}$ from the surface).

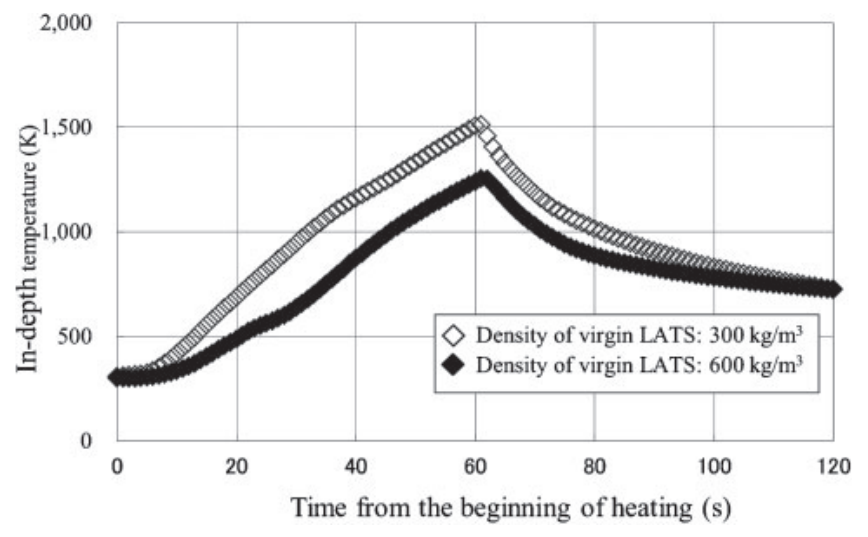

Fig. 19. Time course of in-depth temperature of the $300 \mathrm{~kg} / \mathrm{m}^{3}$ LATS and the $600 \mathrm{~kg} / \mathrm{m}^{3}$ LATS (heating rate: $2.0 \mathrm{MW} / \mathrm{m}^{2}$; duration: $110 \mathrm{~s}$; stagnation pressure: $5.0 \mathrm{~Pa}$; facility: ARD of JAXA) (thermocouple depth: $5 \mathrm{~mm}$ from the surface).

Fig. 18 shows that of the in-depth temperature under the same conditions. ${ }^{11)}$ The measured results for a high-density CFRP (approximately $1,470 \mathrm{~kg} / \mathrm{m}^{3}$ ) are also shown in Figs. 17 and $18 .{ }^{11)}$ These figures show that the time courses of the surface and in-depth temperatures of the LATS and CFRP are almost identical. The maximum heat flux used when designing the REM capsule is approximately $3.1 \mathrm{MW} / \mathrm{m}^{2}$, whereas the real heat flux at re-entry is approximately $1.5 \mathrm{MW} / \mathrm{m}^{2}{ }^{16,29)}$ A comparison of the in-depth temperatures for LATS materials with densities of approximately 300 and $600 \mathrm{~kg} / \mathrm{m}^{3}$ is shown in Fig. 19. ${ }^{11)}$ This figure confirms that the heat shield performance of the LATS depends on density. Appropriate preference of the virgin LATS density can even control the extent of temperature increase inside the heated materials.

In designing a re-entry vehicle, one of the most important issues is determining the thickness of heat shield materials. It is desirable that the in-depth temperature increase and the mass loss rate of heated materials be small. The previously described high-density CFRP was adopted as the heat shield material of an REM capsule used for an atmospheric re-entry flight. Given that the in-depth temperature elevation 
and the mass loss rate of the LATS are approximately identical to those of the high-density CFRP, the LATS may be assumed to be useful for the re-entry flight of the REM capsule.

\subsection{Ablation analysis results}

Ablation analyses of the test models are carried out according to a method similar to that in Ref. 14).

The input data to calculate the thermal behavior of a specimen using the one-dimensional ablation analysis program include parameters such as heating environment conditions, ablator thickness and thermal properties of the materials. These parameters are specified based on measured data and data obtained from the literature.

The cold-wall heat flux, enthalpy and impact pressure are determined based on data measured during the heating test. The thickness of the specimen and the virgin density of the ablator are based on measurements of each model. The char density of each ablator model is determined from the measured carbonized density of the LATS ablators with a virgin density of approximately $200-700 \mathrm{~kg} / \mathrm{m}^{3}$. The emissivity of the char surface is set to $0.85 .^{19,22)}$

The reference value for the thermal conductivity of a virgin material $k_{v \text { ref }}$ is constructed from the measured value of the LATS materials with a density of approximately $300 \mathrm{~kg} / \mathrm{m}^{3}$ (Fig. 2). These data are combined with literature data for the PICA ${ }^{5,6)}$ multiplied by a constant, $c_{P \text { PICA }} \times k_{v \text { PICA }}(T)$, where $k_{v \text { PICA }}(T)$ is the thermal conductivity of the PICA with a density of approximately $300 \mathrm{~kg} / \mathrm{m}^{3}$ and $c_{P \text { PICA }}$ is a constant to connect the two sets of data smoothly. The reference value for the thermal conductivity of the char material $k_{c h \text { ref }}$ is assumed to be the same as that of the virgin material $k_{v \text { ref }}\left(k_{c h r e f}=k_{v \text { ref }}\right)$.

The isobaric specific heat of the char material $c_{p c h}$ is determined from the data of Refs. 19) and 22). It is expressed by

$$
c_{p c h}=c_{\infty} \frac{T}{\sqrt{T^{2}+D^{2}}}
$$

where $T$ is the temperature $(\mathrm{K}), c_{\infty}$ is $2.3 \times 10^{3} \mathrm{~J} /(\mathrm{kg} \mathrm{K})$ and $D$ is $800 \mathrm{~K}$. The specific heat of the virgin material $c_{p v}$ is then given by $c \times c_{p c h}$, where $c$ is a constant determined by considering the measured data of the specific heat of the ablator. The specific heat of the pyrolysis gas $c_{p g}$ is set to a constant value of $1,674.6 \mathrm{~J} /(\mathrm{kg} \mathrm{K}){ }^{22)}$ The coefficients in the Arrhenius equation [Eq. (5)] are determined from the TGA data of the LATS ablator. ${ }^{13)}$ The values of $N=2$, $A_{1}=0.1, \quad f_{1}=3.5 \times 10^{9} \mathrm{~s}^{-1}, \quad B_{1}=1.1 \times 10^{4} \mathrm{~K}, \quad \mu_{1}=$ $100.0, A_{2}=0.9, f_{2}=7.0 \times 10^{3} \mathrm{~s}^{-1}, B_{2}=1.1 \times 10^{4} \mathrm{~K}$ and $\mu_{2}=3$ are used in the calculation.

In particular, for test models with densities that differ from $300 \mathrm{~kg} / \mathrm{m}^{3}$, the thermal conductivities of virgin and charred materials are assumed to differ from $k_{v \text { ref }}$ and $k_{c h r e f}$, respectively. For each test model, the reference thermal conductivities $k_{v \text { ref }}$ and $k_{c h \text { ref }}$ are multiplied by constants, and the new thermal conductivities $c_{k v} \times k_{v \text { ref }}$ and $c_{k c h} \times k_{c h \text { ref }}$ are used for numerical calculations via the analysis program. The constant coefficients $c_{k v}$ and $c_{k c h}$ are tuned so that the mea-

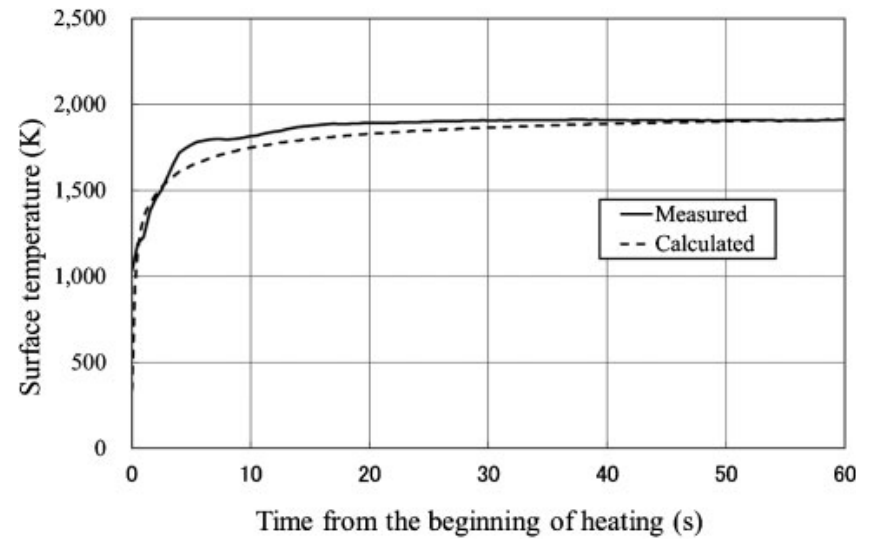

Fig. 20. Comparison of surface temperature $\left(\rho_{v}=568.9 \mathrm{~kg} / \mathrm{m}^{3}\right.$; $\left.c_{w}=0.97 \mathrm{MW} / \mathrm{m}^{2}\right)$.

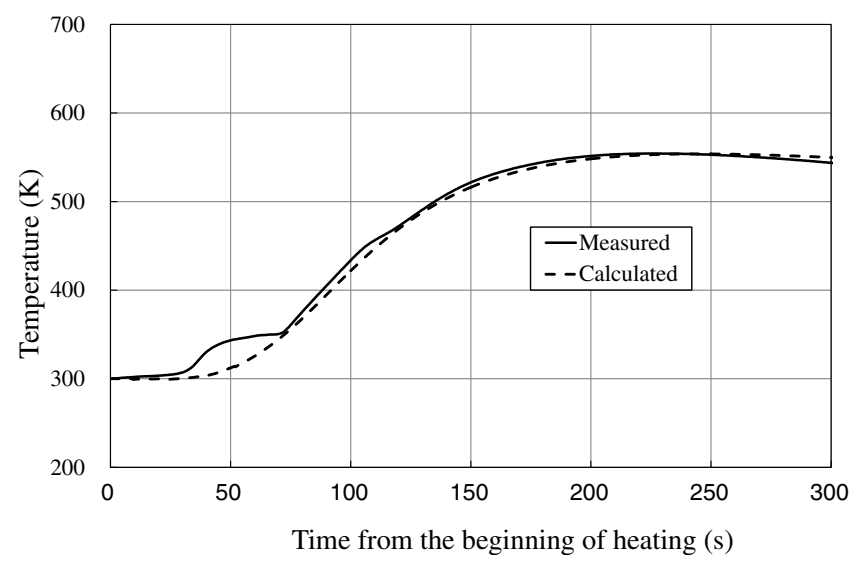

Fig. 21. Comparison of back surface temperature $\left(\rho_{v}=568.9 \mathrm{~kg} / \mathrm{m}^{3}\right.$; $\left.c_{w}=0.97 \mathrm{MW} / \mathrm{m}^{2}\right)$.

sured and calculated temperatures agree well.

Figures 20 and 21 show comparisons between the measured and calculated surface and back-surface temperatures of the LATS model with a virgin density of $544 \mathrm{~kg} / \mathrm{m}^{3}$. The heating test is carried out in the heating facility at the ARD in JAXA. The cold-wall heating rate is $0.97 \mathrm{MW} / \mathrm{m}^{2}$ with a heating time of $60 \mathrm{~s}$. In Fig. 20, the surface temperature rises rapidly to approximately $1,700-1,800 \mathrm{~K}$ in $10 \mathrm{~s}$, and thereafter rises slightly and gradually by a small amount. In Fig. 21, the back surface ( $20 \mathrm{~mm}$ from the heating surface) temperature rises to approximately $550 \mathrm{~K}$ in $200 \mathrm{~s}$. At approximately $35 \mathrm{~s}$, the measured temperature increases rapidly - an aspect not simulated by the present program. Otherwise, the time courses of the surface and back surface temperatures simulated by the analysis program agree well with the measured results.

Figures 22 and 23 show the comparison between the measured and calculated surface and back surface temperatures of the LATS model with a virgin density of $536 \mathrm{~kg} / \mathrm{m}^{3}$. The heating test is carried out in the heating facility at the $\mathrm{L} 3 \mathrm{~K}$ in DLR. The cold-wall heating rate is $11.1 \mathrm{MW} / \mathrm{m}^{2}$ with a heating time of $10 \mathrm{~s}$. In Fig. 22, the surface temperature rises rapidly to more than $3,000 \mathrm{~K}$ in less than $1 \mathrm{~s}$, and thereafter rises slightly and gradually. In Fig. 21, the back surface 


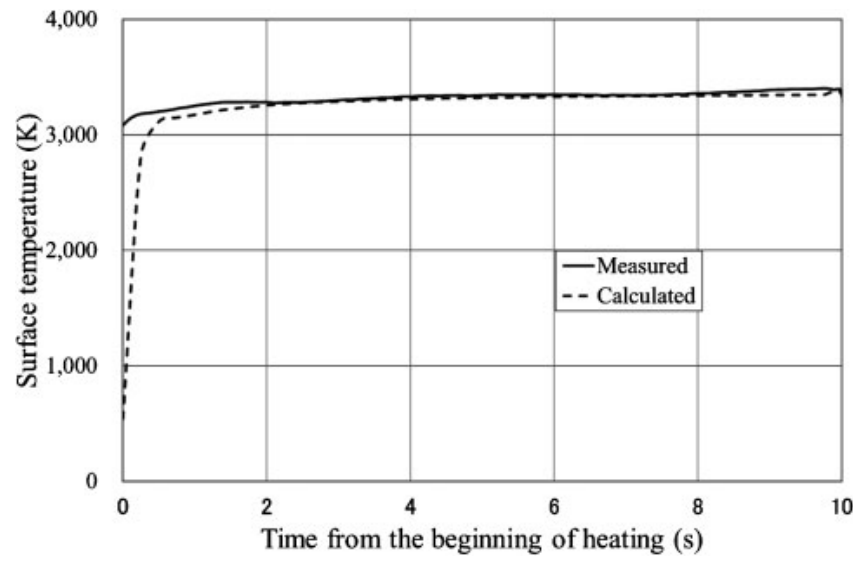

Fig. 22. Comparison of surface temperature $\left(\rho_{v}=536.9 \mathrm{~kg} / \mathrm{m}^{3}\right.$; $\left.c_{w}=11.1 \mathrm{MW} / \mathrm{m}^{2}\right)$.

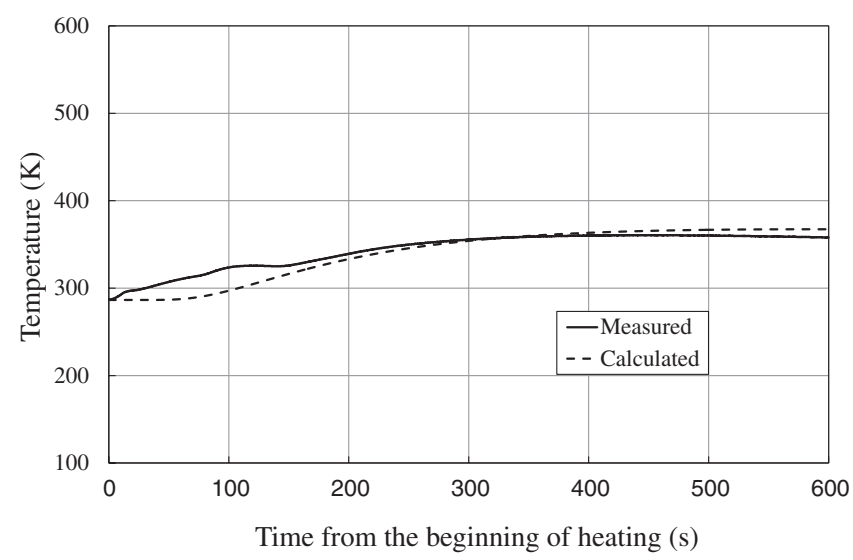

Fig. 23. Comparison of back surface temperature $\left(\rho_{v}=536.9 \mathrm{~kg} / \mathrm{m}^{3}\right.$; $\left.c_{w}=11.1 \mathrm{MW} / \mathrm{m}^{2}\right)$.

( $40 \mathrm{~mm}$ from the heating surface) temperature rises slowly to approximately $350 \mathrm{~K}$ in $200 \mathrm{~s}$ and remains mostly the same during 200-600 s. For the period of approximately 0 to $150 \mathrm{~s}$, the measured temperature is slightly high-a feature not simulated by the present program. This trend is similar to the case in Fig. 21. Otherwise, the time courses of the surface and the back-surface temperatures simulated by the analysis program with a heating rate of $11.1 \mathrm{MW} / \mathrm{m}^{2}$ agree well with the measured results. It is confirmed that the one-dimensional ablation analysis program could estimate the surface and in-depth temperatures under highenthalpy flow.

\section{Conclusion}

A new lightweight CFRP has been developed. Lightweight ablator series specimens fabricated from carbon fiber felt and resin have densities of $\sim 200-1,500 \mathrm{~kg} / \mathrm{m}^{3}$. For charring ablation and thermal response analysis, a computer code has also been developed to simulate the one-dimensional transient thermal behavior of charring materials.

In this paper, the thermal response and ablation characteristics of the LATS under high-enthalpy airflow were described. The validity of the mathematical model and the applicability of the one-dimensional ablation code were also discussed based on an evaluation of a comparison between the simulated and measured results of the arc-heated test. The results of the present study were as follows.

- Several heating tests were performed using the arc-heating equipment at facilities in Japan and Germany. The time courses of surface and in-depth temperatures were acquired under test conditions in which the surface temperature is approximately $1,500-3,500 \mathrm{~K}$ (a heat flux of $500 \mathrm{~kW} / \mathrm{m}^{2}-11.1 \mathrm{MW} / \mathrm{m}^{2}$ for $10-300 \mathrm{~s}$ ). The LATS surface thermochemistry reaction could be described as a reaction in the diffusion-controlled oxidation region.

- The total mass loss rate $\dot{m}_{t}$ of carbon materials such as graphite in the diffusion-controlled oxidation has been expressed by Eq. (7). However, this equation cannot be applied to CFRP, which contains a resin that undergoes thermal decomposition by heating. Therefore, a new index $\theta$ was adopted in this study to predict the mass loss rate. The $\theta$ value of the lightweight ablator series plastic is approximately identical to that of the heat shield material for the re-entry module capsule.

- When a lightweight ablator series plastic (density of $\sim 300 \mathrm{~kg} / \mathrm{m}^{3}$ ) and a CFRP used for the re-entry module capsule (density of $\sim 1,500 \mathrm{~kg} / \mathrm{m}^{3}$ ) were heated under a heat flux rate of $2.0 \mathrm{MW} / \mathrm{m}^{2}$, the surface and in-depth temperatures of the two plastics were almost identical. It is thus concluded that the lightweight ablator series is a promising heat shield material for space vehicles re-entering the atmosphere.

- Simulated results of the surface and back-surface temperatures including the in-depth temperature near the back surface for an ablator of the new series agreed well with measured results. These results suggest that a one-dimensional mathematical model can be applied to ablation analyses of low-density ablators of the new series under a wide range of high-enthalpy flows.

\section{Acknowledgments}

This study was partly supported by a Grant-in-Aid (Researchnumber 21360423) for Scientific Research (KAKENHI) from the Japan Society for the Promotion of Science (JSPS).

\section{References}

1) Milos, F. S.: Galileo Probe Heat Shield Ablation Experiment, J. Spacecraft Rockets, 34, 6 (1997), pp. 705-713.

2) Milos, F. S., Chen, Y. K. and Brewer, R. A.: Analysis of Galileo Probe Heatshield Ablation and Temperature Data, J. Spacecraft Rockets, 36, 3 (1999), pp. 298-306.

3) Kato, S., Kanno, Y., Okuyama, K., Uegaki, E., Yamada, T. and Suzuki, T.: Design and Post-Flight Analysis of REV Thermal Protection System, JAXA Research and Development Report, JAXA-RR04-045, 2005, pp. 77-103 (in Japanese).

4) Okuyama, K., Kato, S., Yamada, T. and Zako, M.: Oxidation Characteristics of the Carbonized CFRP under the Air Environments, TANSO, 213 (2004), pp. 128-133 (in Japanese).

5) Tran, H., Johnson, C., Rasky, D., Hui, F., Chen, Y. K. and Hsu, M.: Phenolic Impregnated Carbon Ablators (PICA) for Discovery Missions, AIAA Paper 96-1911, 31st AIAA Thermophysics Conference, New Orleans, LA, 1996. 
6) Tran, H., Johnson, C., Rasky, D., Hui, F., Hsu, M., Chen, T., Chen, Y. K., Paragas, D. and Kobayashi, L.: Phenolic Impregnated Carbon Ablators (PICA) for Discovery Missions, NASA TM 110440, 1997.

7) Desai, P. N., Mitcheltree, R. A. and Cheatwood, F. M.: Entry Dispersion Analysis for the Stardust Comet Sample Return Capsule, AIAA Paper 97-3812, GNC, AFM, and MST Conference and Exhibit, New Orleans, LA, 1997.

8) Willcockson, W. H.: Stardust Sample Return Capsule Design Experience, J. Spacecraft Rockets, 36, 3 (1999), pp. 470-474.

9) Kobayashi, Y., Sakai, T., Okuyama, K., Suzuki, T., Fujita, K. and Kato, S.: An Experimental Study on Thermal Response of Low Density Carbon-Phenolic Ablators, AIAA Paper 2009-1587, 47th AIAA Aerospace Sciences Meeting Including the New Horizons Forum and Aerospace Exposition, Orlando, Florida, 2009.

10) Suzuki, T., Fujita, K., Sakai, T., Okuyama, K., Kato, S. and Nishio, S.: Evaluation of Prediction Accuracy of Thermal Response of Ablator under Arcjet Flow Conditions, AIAA Paper 2010-4787, 10th AIAA/ ASME Joint Thermophysics and Heat Transfer Conference, Chicago, Illinois, 2010.

11) Okuyama, K., Kanada, T., Kato, S., Sakai, T., Suzuki, T., Fujita, K and Nishio, S.: Thermochemical and Thermomechanical Characteristics of an Ultra Lightweight CFRP under High Temperature Environments, 2011-c-15, International Symposium on Space Technology and Science, Okinawa, 2011.

12) Sakai, T., Inoue, T., Kuribayashi, M., Okuyama, K., Suzuki, T., Fujita, K., Kato, S. and Nishio, S.: Post-Test Sample Analysis of Low Density Ablators Using Arcjet, Trans. Jpn. Soc. Aeronaut. Space Sci. Aerospace Technol., 10, ists28 (2012), pp. 65-71.

13) Suzuki, T., Fujita, K., Sakai, T., Okuyama, K., Kato, S. and Nishio, S. Thermal Response Analysis of Low Density CFRP Ablator, Trans. Jpn. Soc. Aeronaut. Space Sci. Aerospace Technol., 10, ists28 (2012), pp. 21-30.

14) Kato, S., Okuyama, K., Gibo, K., Miyagi, T., Suzuki, T., Fujita, K., Sakai, T., Nishio, S. and Watanabe, A.: Thermal Response Simulation of Ultra Light Weight Phenolic Carbon Ablator by the Use of the Ablation Analysis Code, Trans. JSASS Aerospace Technology Japan, 10, ists28 (2012), pp. Pe_31-Pe_39.

15) Kato, S., Okuyama, K., Nishio, S., Sakata, R., Hama, K. and Inatani, Y.: Numerical Analysis of Charring Ablation for Ablative Materials of Re-Entry Capsules, J. Jpn. Soc. Aeronaut. Space Sci., 50, 582 (2002), pp. 255-263 (in Japanese)

16) Kato, S., Okuyama, K. and Yamada, T.: Validation and Post-Flight Analysis of the Ablation Analysis Code, JAXA Research and Development Report, JAXA-RR-04-045, 2005, pp. 31-54 (in Japanese).
17) Moyer, C. B. and Rinadal, R. A.: An Analysis of Coupled Chemically Reacting Boundary Layer and Charring Ablator, Part II, Finite Difference Solution for the In-Depth Response of Charring Materials Considering Surface Chemical and Energy Balances, NASA CR-1061, 1967.

18) Chen, Y. K. and Milos, F. S.: Ablation and Thermal Response Program for Spacecraft Heatshield Analysis, J. Spacecraft Rockets, 36, 3 (1999), pp. 475-483.

19) Potts, R. L.: Application of Integral Methods to Ablation Charring Erosion, A Review, J. Spacecraft Rockets, 32, 2 (1995), pp. 200-209.

20) Metzger, J. W., Enge, M. J. and Diaconis, N. S.: Oxidation and Sublimation of Graphite, AIAA J., 5, 3 (1967), pp. 451-460.

21) Park, C.: Effects of Atomic Oxygen on Graphite Ablation, AIAA J., 14, 11 (1976), pp. 1640-1642.

22) Potts, R. L.: Hybrid Integral/Quasi-Steady Solution of Charring Ablation, AIAA/ASME 5th Joint Thermo Physics and Heat Transfer Conference, Seattle, WA, 1990.

23) Okuyama, K. and Zako, M.: Surface Mass Loss Characteristics of Carbonized Phenolic CFRP in Nitrogen Gas Atmosphere, TANSO, 214 (2004), pp. 184-190.

24) Hanawa, K., Ishii, M. and Matsumoto, M.: Development of Erosion Testing Machine as High Enthalpy Arc-Heated Wind Tunnel, The Symposium on Ultra-high Temperature Materials, Tajimi, Gifu, 1992 (in Japanese).

25) Matsuzaki, T., Ishida, K., Watanabe, Y., Miho, K., Itagaki, H. and Yoshinaka, T.: Construction and Characteristics of the $750 \mathrm{~kW}$ Arc Heated Wind Tunnel, NAL-TM-760, Technical Memorandum of National Aerospace Laboratory, 2001 (in Japanese).

26) Akeo, S., Funatsu, M., Shirai, H., Watanabe, Ya., Ito, T. and Ishida, K.: Characteristics of Radiation in Shock Layer of $750 \mathrm{~kW}$ Arc-heated Wind Tunnel, Symposium on Flight Mechanics and Astrodynamics, 2003, pp. 99-102 (in Japanese).

27) Koch, U., Gülhan, A. and Esser, B.: Two Dimensional Spatially Resolved Two Photon Oxygen Atom Laser Induced Fluorescence Measurements in the Flow Field of the Arc Heated Facility L3K, Proceedings of the Fifth European Symposium on Aerothermodynamics for Space Vehicles (ESA SP-563), Cologne, Germany, 2004, pp. 493-500.

28) Lundell, J. H. and Dickey, R. R.: Performance of Charing Ablative Materials in the Diffusion-Controlled Surface Combustion Regime, AIAA J., 6, 6 (1968), pp. 1118-1126.

29) Okuyama, K., Kato, S., Kanno, Y. and Yamada, T.: Research and Development of REV Ablator in Arc Windtunnel, JAXA-RR-04-045, 2005, pp. 55-75 (in Japanese). 